\title{
Social Learning as a Vehicle for Complementary Strategies in
}

\section{Forest Resource Management}

\author{
Felix Kwabena Donkor ${ }^{1 *}$ \\ ${ }^{1}$ School of Animal, Plant and Environmental Sciences, University of the Witwatersrand, WITS, South \\ Africa \\ *Felix Kwabena Donkor, E-mail: felixdonkor2002@yahoo.co.uk, 1239639@students.wits.ac.za
}

\begin{abstract}
Cooking is a daily activity often based on energy to satisfy individuals' nutritional requirements. Wood fuels are the main source of fuel in rural areas of Africa with detrimental health, environmental and livelihood effects. The study investigates how heavy dependence on wood fuels and the resultant degradation of scarce forest resources can be addressed employing social learning coupled complementary strategies. The qualitative method was used carry out the research in the West Gonja District of Ghana. The case study approach was complemented with Rapid Rural Appraisal (RRA) techniques to gather data from key informants, households and focus group discussions. The use of wood fuels is having a negative impact on critical rural resources such as forest ecosystem services which underpin land-based livelihoods of the study area. The continuous knowledge co-production and utilization within the context of social learning is vital for enhancing adaptive capacity of vulnerable livelihoods especially those reliant on forest resources. Moreover it is crucial to integrate complementary knowledge systems as per social learning and harness appropriate technology when introducing interventions that enable communities to shift to alternative fuel sources. This helps to reduce pressure on communal forest resources and enhance forest conservation with spin-offs for sustainable development.
\end{abstract}

\section{Keywords}

forest resource management, social learning, rural livelihoods, indigenous knowledge

\section{Introduction}

Anthropogenic climate change has been given several terms from "wicked problem” (Rittel \&Webber, 1973) to a "super wicked problem" (Levin, 2012). A common thread in both phrases is that, due to its highly convoluted nature, climate change defies straightforward solutions. Hence in addressing complex problems in the Anthropocene, response interventions require a cross-disciplinary approach (Levin, 2012). This has become more urgent as human-environment relations have been foregrounded in key policy documents such as the Millennium Ecosystems Assessment and the Sustainable Development Goals (SDGs) in an attempt to enhance human wellbeing and quality of life on the planet. Forest resources represent one of such areas where such complex human environment relations deserve 
attention for their sustainable management (Bagoora, 2012). Moreover, forest degradation complemented by climate change and population growth represents some of the urgent problems of our modern society with Africa being the most affected (Fisher et al., 2010). Rural communities in Africa are often poor and thus bear the brunt of climate fluctuations, because of their natural resource-dependence and climate-sensitive livelihoods (Bagoora, 2012). Consequently, ensuring environmental sustainability features prominently in both the Millennium Development Goals and the Sustainable Development Goals (SDGs) of the United Nations.

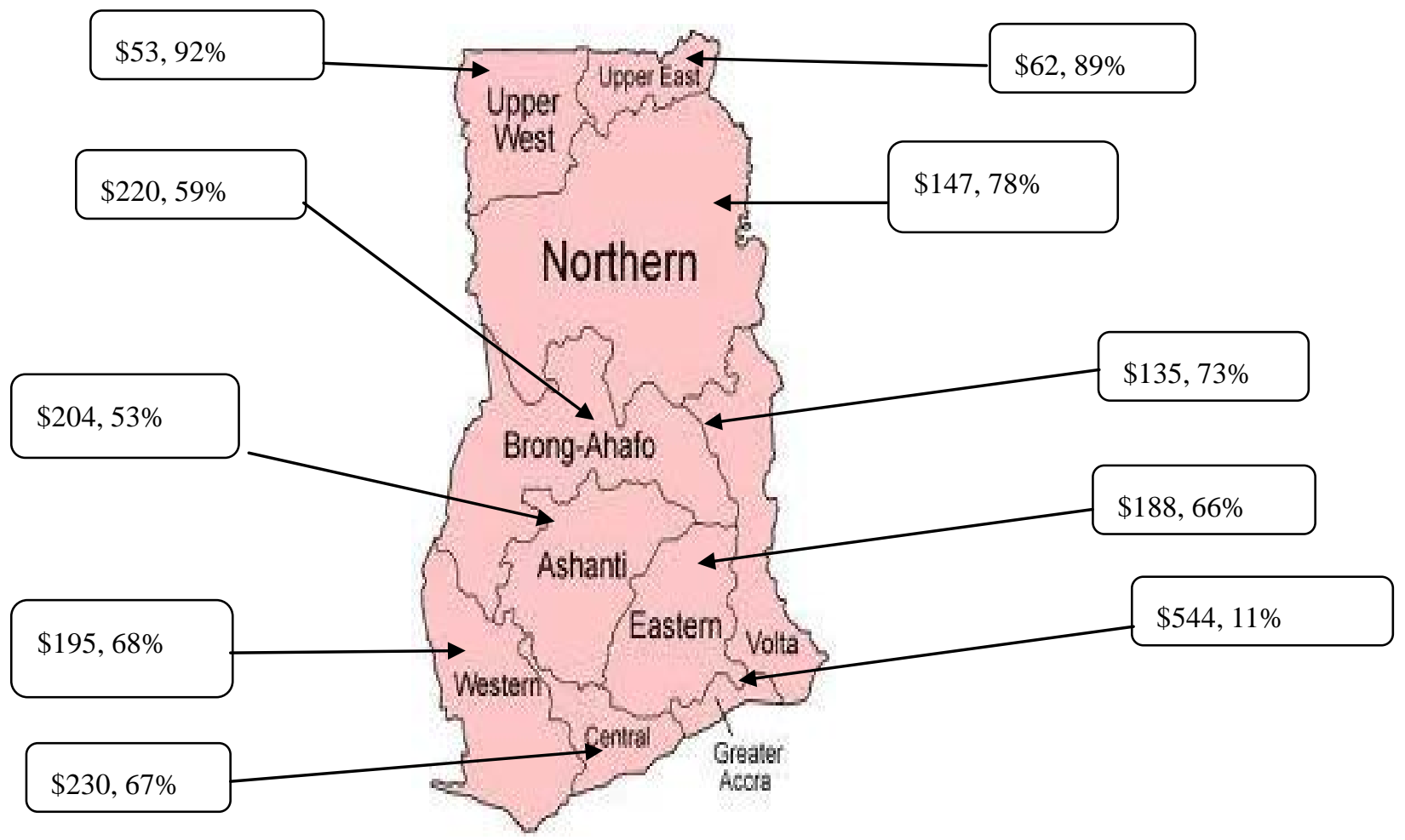

Figure 1. Proportion of Rural Residents in Regions and Mean Annual Income in Ghana

Source: Adapted from Global Alliance for Clean Cookstoves (2012)

Figure 1 depicts the three northern regions of Ghana which all have high rural populations. In Ghana, such remote rural areas are remarkably poor in comparison to urban regions. More over areas with heightened populace of rural residents have lower incomes and are related with substantial use of woodfuels (Zhou et al., 2011). Consequently, in general the northern areas rely heavily on the use of woodfuels in comparison to the other areas (Energy Commission, 2012).

Revenue from the exploitation of environmental resources, collected from non-cultivated habitats like forests are a core source of sustenance for rural livelihoods in tropical forest areas, and is steered by a function of cultural and gender roles (Resurrection \& Elmhirst, 2012). However, often the dearth of insight into intra-community characteristics and factors calls for increased research to better appreciate Published by SCHOLINK INC. 
the relationships between communities, climate change, poverty and natural resources in such dynamic contexts (Resurrection \& Elmhirst, 2012). Thus ultimately the problem of biological diversity loss, erosion of cultural diversity and the poverty phenomenon are intimately connected, requiring a holistic response approach (Elbra, 2013). Moreover, "Sustainable development" as per the United Nations Conference on Environment and Development (UNCED) inspires proactive engagement with local-level response solutions (Leach et al., 1999). This notion has been widely accepted by governments, Nongovernmental Organizations (NGOs) and other civic organizations-demanding for "co-management", or the allocation of roles in the management of natural resources amongst key stakeholders (Dyer et al., 2014). Although this idea undergirds a number of Community-Based Natural Resource Management (CBNRM) initiatives (Dyer et al., 2014), others contend that CBRM aside its advantages often does not succeed in realizing the twin objectives of conservation and sustainable livelihoods (Leach et al., 1999). Kerr et al. (2010) also posit that the dual aim of social development and environmental conservation is delusive and failure prone. Nonetheless, in the face of palpable climate impacts on vulnerable livelihoods in the global south, there is the need to adopt interventions that will help secure vulnerable livelihoods such as forest resource dependent ones (Sayer et al., 2013). Adaptation is vital as it capacitates systems to deal with and modify so as to limit the deleterious impacts while maximising the opportunities (Mudombi et al., 2017). Furthermore, the complex nature of climate impacts is such that it necessitates the involvement of diverse stakeholders. In the absence of consensus, it is challenging for stakeholders to collaborate fruitfully to execute initiatives. Social learning has been fore-grounded as a viable approach to managing human-environment relations like forest resources (Mudombi et al., 2017).

Social learning is a continuous adaptive process of knowledge co-production, reflection and synthesis that can improve people's consciousness about climate change and its effects, with positive results for their adaptive capacity (Mudombi et al., 2017). The objective of this research is to contribute to knowledge on the use of social learning as a tool for enhanced forest resource management in vulnerable rural communities with the West Gonja District of Ghana as a case study.

The intricate connections between the thematic areas of the paper is illustrated in the proceeding diagram. 


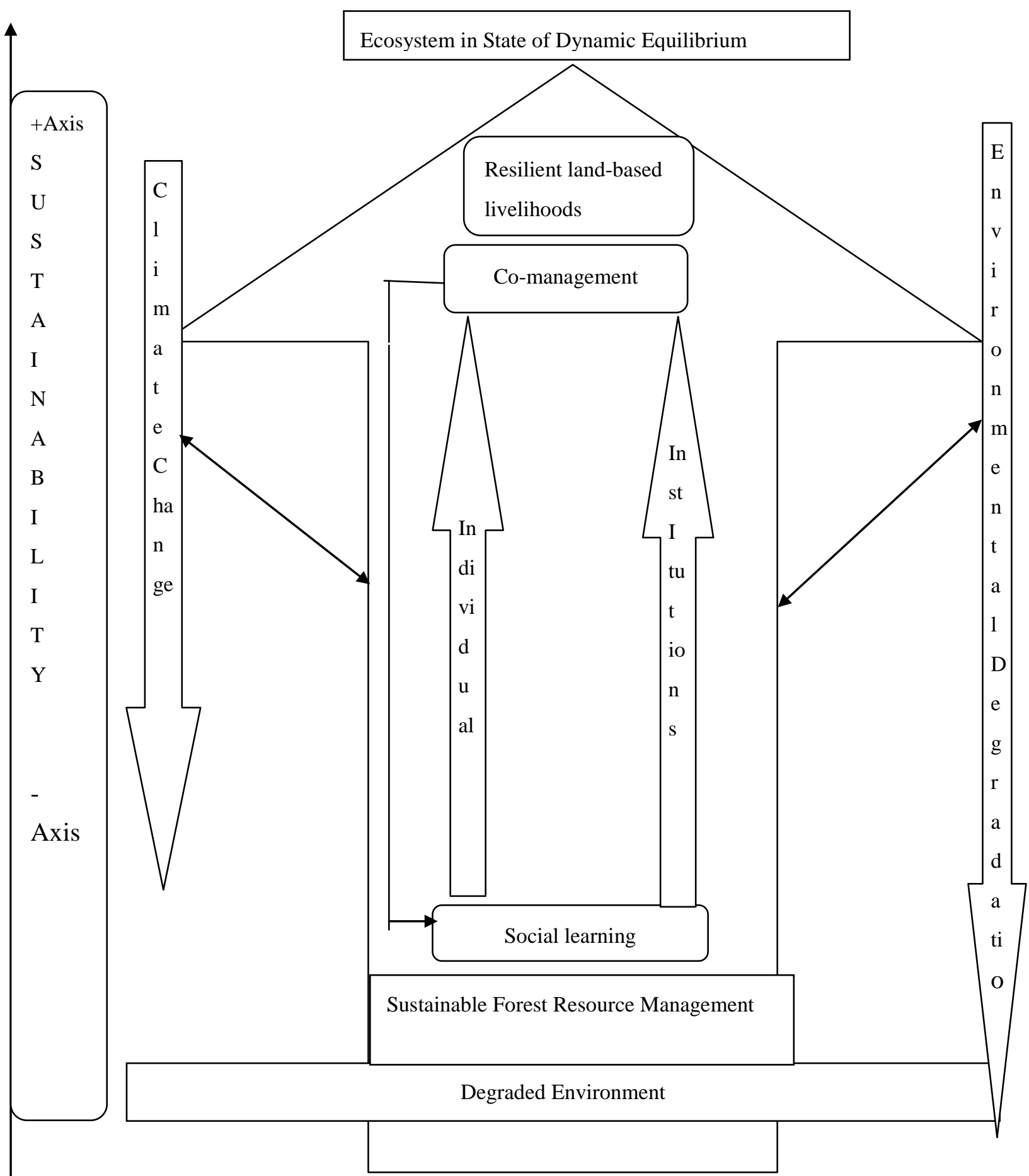

Figure 2. Flow Diagram of Thematic Areas of the Study

Climate change (through its effects such as increased temperatures, drought, seasonal variations and precipitation) has consequences for the sustainable management of forest resources (Figure 2). Furthermore, ecosystem degradation, such as uncontrolled deforestation and unsustainable harvesting Published by SCHOLINK INC. 
of natural resources, aggravate the impact of climate change and compromise the sustainable management of resources (Leach et al., 1999). At the rural level, livelihoods are intimately woven with nature thus the twin impact of climate change and ecosystem degradation on environmental resources equally affect people's livelihoods (Kerr et al., 2010). In response to such environmental stimuli, societies roll out new interventions through social learning to secure their livelihoods (Mudombi et al., 2017). These response measures mediated by rural policy, institutional and individual factors may not be ideal, or effective in sustainably managing the targeted natural resource per se but may simply be experimental.

With time, the environmental feedbacks from are evaluated and society tailors the management approach accordingly in the light of novel evidence and knowledge. The community then enhances the approach as per their unique socio-economic and environmental condition.

\section{Method}

\subsection{Research Design}

This research is undertaken from the case study approach. Kvale and Brinkman (2012) argue that immersing oneself in the target population will usher the researcher into the socio-cultural life of the people and afford an inkling of what the subjects may articulate. This also helps unveil crucial ethicopolitical concerns which need to be considered at both the pre and post interview phases.

\subsection{Information Gathering}

\subsubsection{Literature Reviews}

Some of the main documents perused include Park Management Report of the Mole National Park (2011), Millennium Ecosystems Assessment (2005), Rural Livelihoods and Diversity in Developing Countries by Frank Ellis (2000), Ghana Government Policies on natural resources. These documents helped understand the status quo on the various themes of the research.

\subsection{Data Collection}

\subsubsection{Field Work and Personal Observation}

In addition to the secondary data studied, primary data was sought by visiting the field. Thus the case study site was visited which enabled interaction with households, school children, and some key informants as a way of participant observation.

\subsection{Sampling}

Given resource constraints as per time and funds, interviews were done with 30 households; 5 NGO’s with a record of active participation in the rural energy landscape; 3 tertiary institutions which are into household improved cooking technology for the local market; and two government institutions.

\subsubsection{Choice of Interviewees}

The choice of respondents was carefully chosen and was informed by assessing global and country efforts at addressing the household energy challenge. For example, borrowing from past experiences, the United Nations as part of its post-2015 development agenda, has sought to ensure: The roles of Published by SCHOLINK INC. 
women are given prominence; youth and education play key roles; multi-sectoral approach is used in addressing energy goals; the private sector is involved as a vital player in the delivery of its goals (IISD, 2013). Furthermore, the Country Action Plan of Ghana on Sustainable Energy for all identifies the need for collaboration and concerted action between government, civil society, research community and the private sector (Energy Commission, 2012).

\subsubsection{Sampling Method}

The purposive/snowball sampling approach was employed given the time and other resource constraints. A desk study was done to identify key stakeholders who are active in the field of study and were recruited as key informants (purposive sampling). Some of the key informants consulted include; a local chief, the district assembly planner (Damongo District Assembly), school teachers at the district level (Damongo LA Primary and Bowena Primary and Junior High School), lecturers at the tertiary institutions dealing with energy/fuel (University of Ghana, Kwame Nkrumah University of Science and Technology, Kumasi Polytechnic), divisional heads of civil society organisations (AROCHA, SIMAVI/New Energy).

\subsubsection{Interviews}

The informed consent of the interviewees was sought in each case before being interviewed. In cases where the interviewer preferred the interview in the local dialect, the interview was conducted with the aid of an interpreter. After getting the consent of the interviewer, a semi-structured interview was conducted as per the objectives of the project. Key resource persons from several institutions were interviewed as well as group discussions with school children and facilitated by their teacher. Difficulties or barriers to effective interaction between adults and children could be overcome when kids are interviewed in natural settings. Group discussions were conducted with school children at the playground. Consent was sought from the local chief and parents.

\subsubsection{Interviews with Households}

A number of households were visited (Figure 3), observed and interviewed. These households were within communities where the local AROCHA operates (AROCHA communities). A household is a social unit which exhibits coresidency, often having a common catering arrangement and jointly shares resources (Ellis, 2000). The household is also a basic unit of enumeration used by the Ghana Statistical Service for its Housing and Population Census. The 5 communities visited were Yazori, Murugu, Mognori, Bowena, and Damongo. 


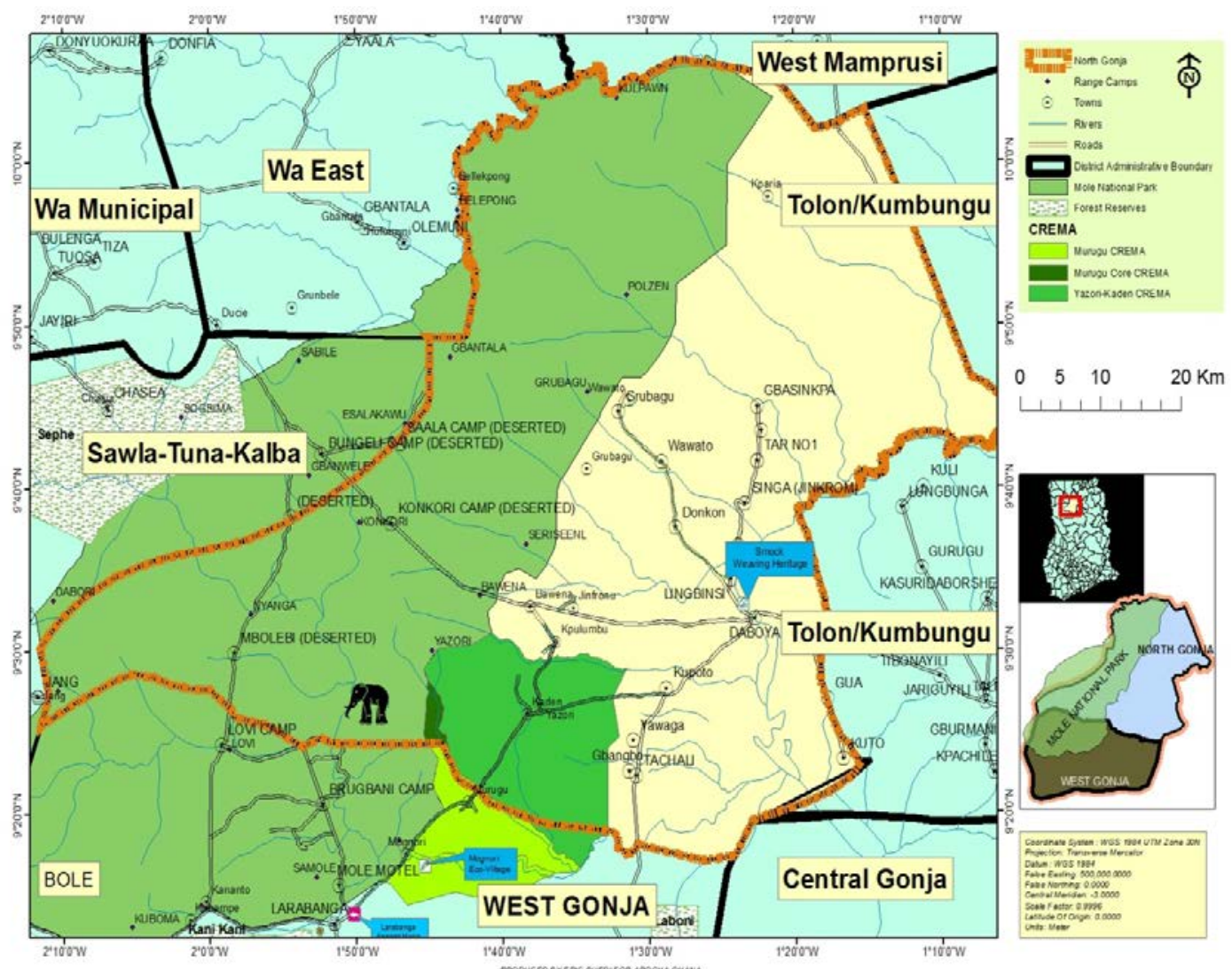

Figure 3. Map of Case Study Area

Source: AROCHA 2013

Figure 3 showcases the case study area which is a farming community with low rates of literacy and low income.

Ownership of land is communal "under the custody of the Tendana (Earth-priest), held in trust by the Chief of the community on behalf of the Divisional Chief (Wasipe-wura) with overall custody entrusted to the Yagbon-wura, the Gonja King" (AROCHA, 2007). The Tendana in the community acts as the overseer of all natural resources within the communities and thus has immense influence in the use of resources. Generally, the communities are farm/hunter groups preoccupied with rain-fed agriculture. In the protracted dry season, most households partake in small-non-farm farm activities such as: Shea butter production, Gari (grated cassava in mashed form) processing, which enhance household incomes. These activities are largely household based, cyclic and arduous with women as the main players.

Selection of households: In line with local traditions, a courtesy call was rendered the chief when visiting a community to explain the rationale of the visit. After gaining the consent of the chief, the chief's household became the first household for interview. Every second household was then chosen in a clockwise manner e. g. 3, 5, 7. 


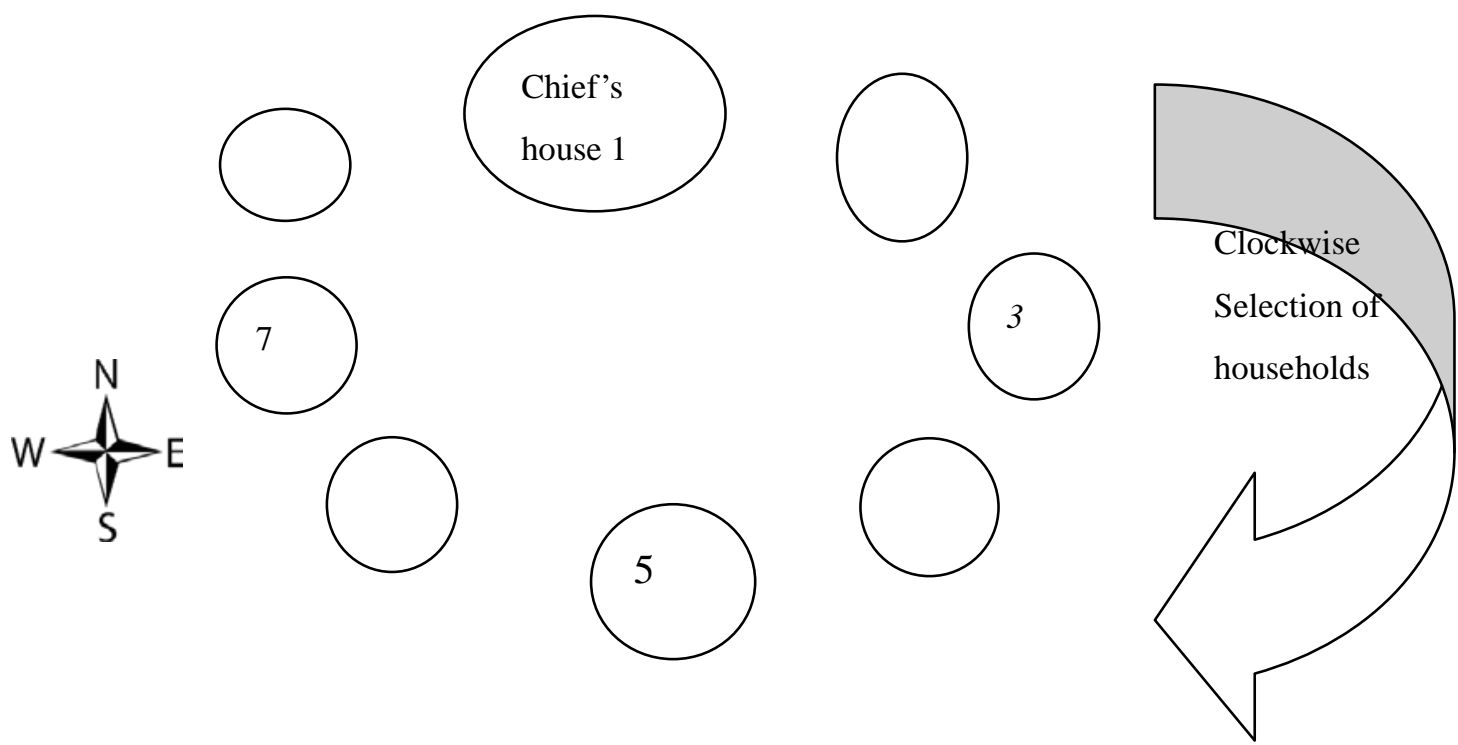

Figure 4. Schematic Overview of Household Selection in the Villages

Figure 4 demonstrates the order of selection of households and the interview process in the rural villages.

The village is composed of mainly adobe houses which are roofed with thatch. Each compound comprised of a husband (head of household), his wife/wives and children in a globular compound. In each household, household head was contacted when present before initiating the interview with the wife. In some cases where the household head was absent, the most senior of his wives served as head and permission was requested from her.

\subsection{Data Validity and Representativeness}

The study aim is to produce knowledge can be used to tackle similar themes in other real-life cases. The Gonja District is a critical case as both Management Plan of the Mole National Park (largest nature reserve in Ghana), as well as key national policy documents on energy emphasize to the harmful impacts of wood fuels on the study area (Energy Commission, 2012). To ensure validity, a number of methods to collecting data were used; group discussions, household/key informant interviews, and personal observation. Furthermore, to boost triangulation, a number of households from diverse villages were interviewed. In addition, the key informants were chosen from diverse stakeholder groups to provide a comprehensive view of the energy challenge at the rural household level. Finally, the questionnaires were made so as to be easily comprehensible to the respondents.

\subsection{Data-Interpretation}

Notes were taken in the course of the interview on thematic areas of the study and complemented with interview recordings. The pertinent thematic areas were composed into statements à la meaning condensation. Meaning condensation is whereby the meanings as expressed by a respondent are summarized into brief formulations. Long accounts are compressed into concise statements where the major issue articulated is reproduced more succinctly (Kvale \& Brinkman, 2012).

Published by SCHOLINK INC. 


\subsection{Qualitative Research and Ethics}

The key research ethics encapsulated in the Belmont Report of 1979 as per human subjects in research were observed (OHRP, 2012). These include Respect for persons: The human dignity of the respondents was respected hence their consent was sought throughout the study. Beneficence the respondents were interviewed in safe serene environments. Justice: Copies of the research were shared with the community leaders since research participants deserve to share in the benefits of the study. In modern times, Respect for communities has emerged as another aspect of ethics, consequently the norms and traditons of the local community were respected.

\section{Result}

The results of key stakeholder interviews are illustrated in the following table highlighting how social learning factors can facilitate complementary strategies for communal forest resource management.

Table 1. Complementary Strategies for Forest Resource Management through Social Learning

Thematic area

1. Individual level

Willingness to share ideas/information and participation by all stakeholders

Continuous interaction and feedback

Flexibility in planning and implementation
Relevant Comments

“Awareness creation must be increased to conscientise people on the risk of woodfuels and the degradation of forest resources. This is necessary as people are used to collecting fuel free of charge and thus making the shift will involve a lot of education.” Respondent A; an engineer with an international NGO "Our local taboos include trees that should not be cut to avoid punishment from the deities. Example trees, such as shear tree (vitellaria paradoxa) and dawadawa (Parkia biglobosa) are prohibited for woodfuel due to the economic value attached to them by the local authority.” Respondent B; a local chief

"Knowledge of the livelihood patterns of a constituency to which a project is tailored is another important factor. This helps to enhance co-management and/or co-ownership of the product as well as eventual buy-in.” Respondent C; a social scientist dealing sustainable livelihoods 
Existence of processes to translate feedback into changed practices

Support for locally initiated projects

Development of local stakeholders’ capacity to engage with projects or interventions
"On the whole there are varied possibilities for reversing the present heavy dependency on woodfuels, however the main challenge is with making these alternatives accessible to the rural households. This is one vital role of the mediating institutions like government, companies and organisations of the private sector.” Respondent $\mathrm{D}$; an energy expert with a local NGO

"The briquettes produce little pollution and make use of abundant waste materials. This is in line with appropriate technology concept of using readily available local materials to limit production costs.” Respondent E; an energy expert at a local university "With regards to appropriate technology, the Energy Commission is promoting sustainable woodlot cultivation with a pilot project at Egyirapa. Moreover the production technology is being enhanced. The traditional carbonisation technology using the earth mound is inefficient thus it wastes a lot of wood to produce little charcoal. Consequently, the Energy

Commission is promoting the use improved technology like the cylindrical metal kiln, brick kiln which produce much denser fuel and are more efficient in their wood to energy conversion.” Respondent E; a project manager with the national Energy Commission

3.1 Results from Key Informants Interview for Informing Complementary Inteventions on Forest Conservation

In answer to the question Can wood fuel/charcoal be replaced to help reduce pressure on forest resources in your community?

Out of 13 key informants interviewed 10 (78\%) answered in the affirmative and were optimistic that the heavy dependence on woodfuel can be reversed. 


\section{Can Woodfuel be Replaced?}

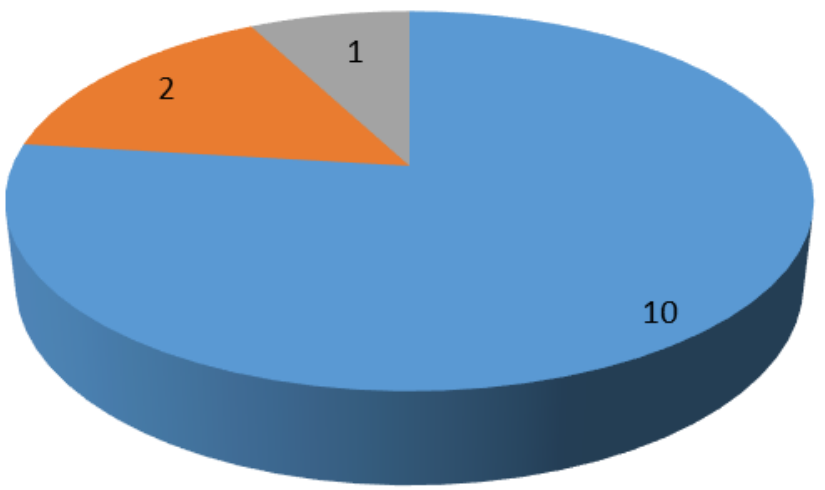

Yes

No

Maybe

Figure 5. Perception on Substitutability of Woodfuels to Help Reduce Pressure on Community Forests

Figure 5 demonstrates the level to which the key informants view the substitutability of woodfuels. However, 2 (15\%) answered in the negative indicating this is not possible whilst one respondent (8\%) was indifferent. Thus there is an overwhelmingly constituency, within key informants community which see it feasible to substitute the heavy dependence on woodfuels.

In a quest to gain insight into factors influencing respondents' choice of fuel, they were asked their What is/are your reason(s) for preference for choice of fuel to feed in the tailoring of complementary strategies that will reduce pressure on scarce forest resources?

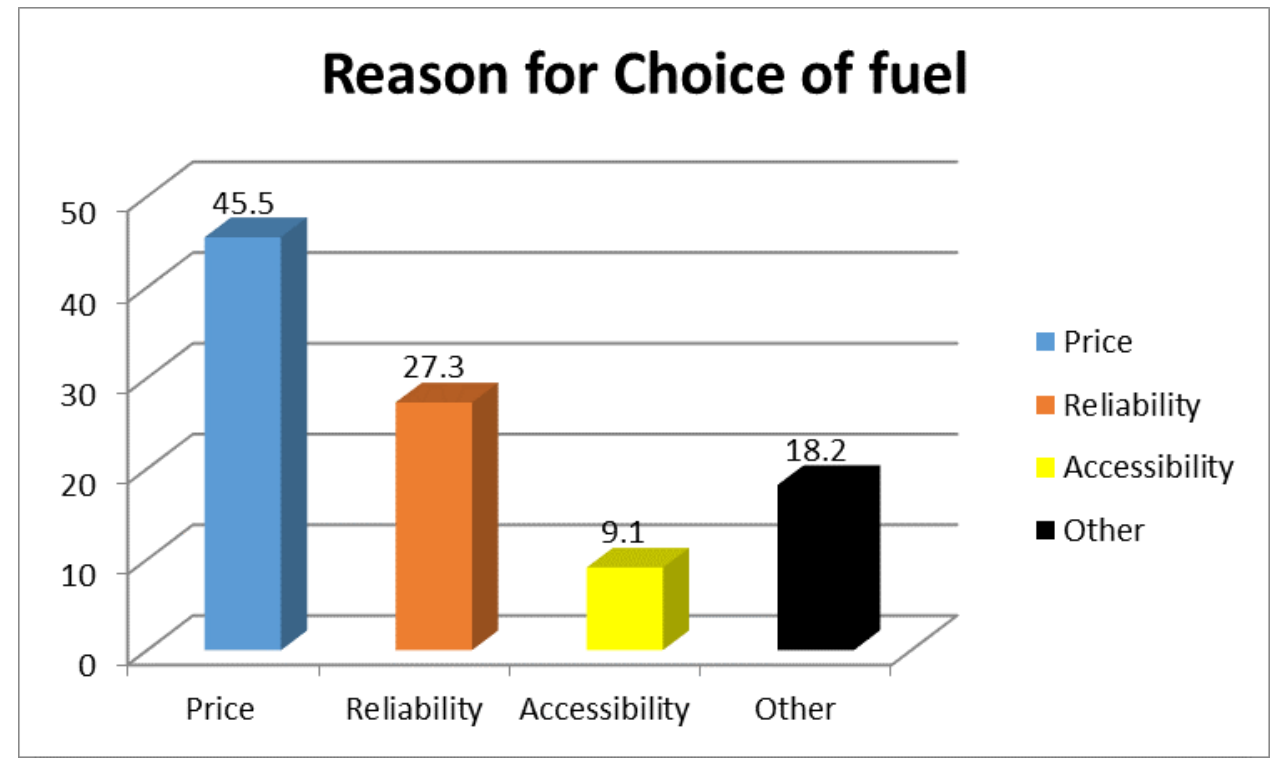

Figure 6. Reason for Respondent's Choice of Fuel 
Figure 6 portrays the different reasons informing the choice of fuel used by the respondents. Cost of fuel was the main reason for the decision to adopt a particular fuel (45.5\%), followed by reliability of the fuel type (27.3), other reasons relating to issues such as the safety of the fuel, ease of use represent $18.2 \%$ whilst accessibility was the concern of $9.1 \%$ of the respondents.

In general, respondents indicated their willingness to adopt modern cooking technologies should they be in a situation to afford it. Hence $72.7 \%$ of respondents registered their desire to shift to cleaner cooking options whilst 27.3 suggested they preferred their current choice and would not be willing to make a substitute for other options.

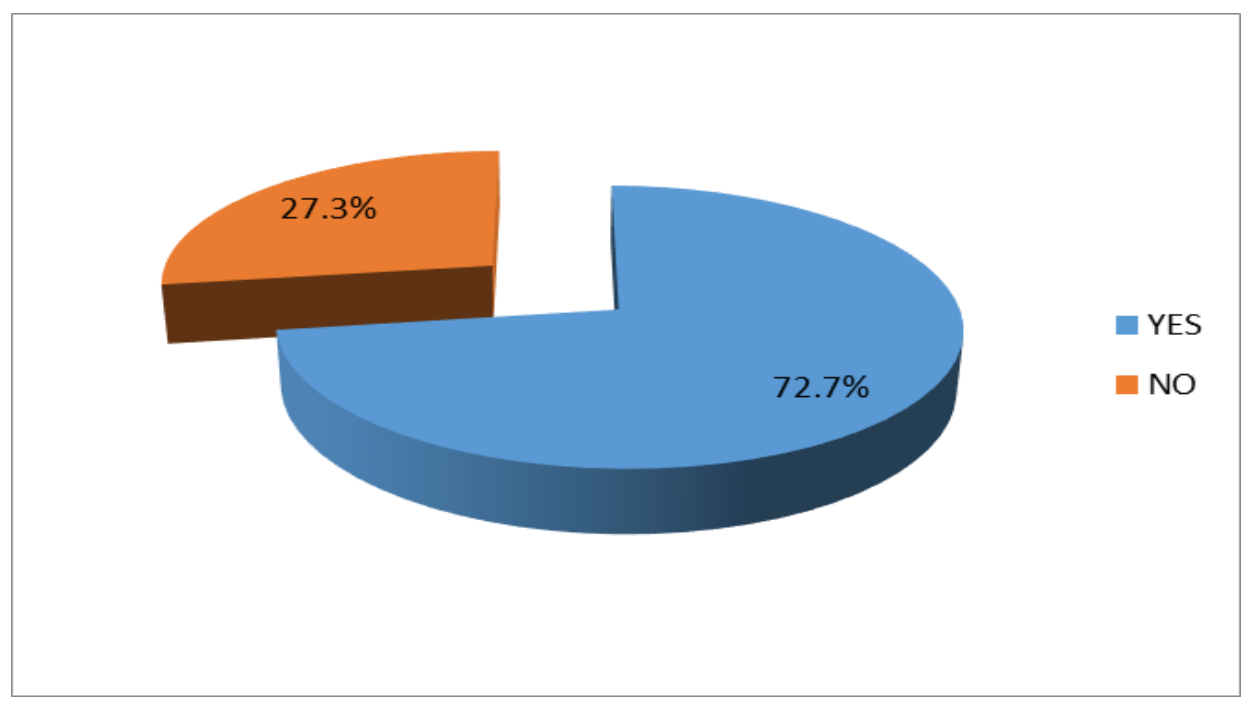

Figure 7. Willingness to Adopt New Technology

Figure 7 showcases respondent's willingness to shift to cleaner fuels to reduce pressure on forest resources. The general goodwill for modern fuels suggests respondents will be receptive to cleaner fuel options. This willingness however is shaped by factors such as price, reliability, accessibility which must be made bearable by the mediating institutions.

Respondents were also asked to indicate their primary fuel used and the size of their households.

Table 2. Main Source of Fuel of Respondent and Household Size

\begin{tabular}{cccccccc}
\hline & & \multicolumn{5}{c}{ Range of household size } & \multirow{2}{*}{ Total } \\
\cline { 3 - 6 } & & $<5$ & $5-10$ & $11-15$ & $16-20$ & $>20$ & \\
\hline \multirow{2}{*}{$\begin{array}{c}\text { Main source } \\
\text { of fuel of }\end{array}$} & Fuelwood & 2 & 16 & 2 & 2 & 1 & 23 \\
$\begin{array}{c}\text { respondent } \\
\text { Charcoal }\end{array}$ & 4 & 1 & 0 & 0 & 0 & 5 \\
\multicolumn{2}{c}{ Total } & 1 & 1 & 0 & 0 & 0 & 2 \\
\hline
\end{tabular}

Published by SCHOLINK INC. 
Table 2 describes the relationship between household sizes and the type of fuel used. Families using fuelwood have big family sizes, majority of them (16) within the 5-10 range, 2 within the 11-15 range, another 2 belonging to the 16-20 range, one household with members over 20 and 2 other households with members less than 5 . On the other hand families using charcoal were mostly with members within a range of 5 with only one house within the 5-10 range. Of the two families using gas as a fuel source, one was within the 5 range and the other fell within the 5-10 size range.

Several of the literature consulted (e. g., MPMP, 2011, p. 44) also suggested that fringe communities turn to the park to meet their fuel needs due to shortage of woodfuel sources beyond the borders of the park. Thus the case study also afforded the chance to inquire how proximity of a locale to the National Park may affect the number of hours spent searching for fuel which would in turn give an indication as to how prevalent this phenomenon is within the fringe communities. Furthermore, the time spent in searching for fuel is an opportunity cost as it could have been used in more productive ventures which would help improve their livelihoods. Consequently How much time do you spend in searching for fuel? was a question posed to respondents to gauge this view.

Table 3 denotes the number of hours invested in the search of woodfuel by respondents from various locations.

Table 3. Number of Hours Spent Searching for Fuelwood

\begin{tabular}{ccccccccccc}
\hline & \multicolumn{8}{c}{ number of hours spent searching for fuelwood } \\
\cline { 3 - 10 } & & 1 & 2 & 2.5 & 3 & 3.5 & 4 & 4.5 & 5 & Total \\
\hline \multirow{3}{*}{ Fuelsource } & Fuelwood & 2 & 6 & 2 & 6 & 1 & 2 & 1 & 3 & 23 \\
& charcoal & 0 & 3 & 0 & 2 & 0 & 0 & 0 & 0 & 5 \\
\multirow{3}{*}{ Total } & gas & 0 & 2 & 0 & 0 & 0 & 0 & 0 & 0 & 2 \\
\hline
\end{tabular}

An SPSS statistical analysis produces a Pearson chi-square significance value of 7.850 ( $P>0.05)$, which is insignificant. This outcome suggests there is no correlation between the location of a household and the number of hours spent in search of fuel. This indicates that the time invested to find fuel in a fringe community such as Mognori (o km from the park), does not differ from Bawena (5 km from Park), Murungu (8 km from park), nor Yazori (14 km from park) bordering the Mole National Park. Thus respondents generally spend between 2-3 hours in search of wood irrespective of location. This infers people in the fringe communities avoid the park and gather woodfuel at a different location which is good for the purpose of conserving the park's resources.

Most of the respondents had suffered a health challenge due to the use of fuelwood and charcoal as showcased in Figure 8 below in response to the question Have you had any health challenge related to 
this method of cooking?

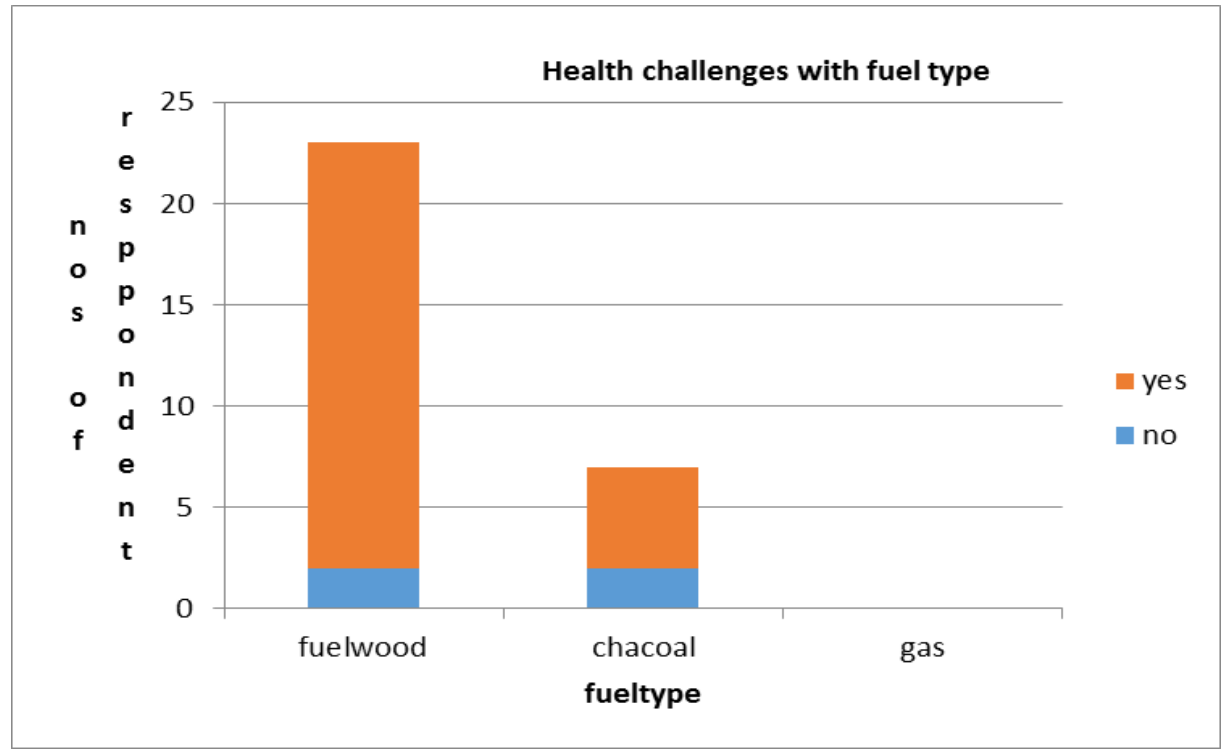

Figure 8. Health Challenges with Choice of Fuel

Of 23 respondents using fuelwood, 21(90\%) respondents reported health challenges. Also 5 (71\%) respondents out of 7 charcoal users indicated they have had health challenges with use of charcoal. Only gas users reported no health challenge. This suggests charcoal is comparatively cleaner than fuelwood and thus poses less threat to the health of respondents and therefore will be less detrimental to their livelihood.

\subsection{Harvesting of Woodfuels amongst School Kids}

In Mognori, out of the total 33 respondents, all 16 males (100\%) indicated they are not sent to fetch firewood. They rather assist their parents on the farm. All the females 17 (100\%) on the other hand reported that they are sent to collect firewood from neighbouring forest for the house. The same scenario was recorded in Bowena where out of 25 respondents, all 11 males revealed they do not search for fuelwood in contrast to the 14 females who admitted being sent to collect firewood.

\section{Discussion}

At the individual level social learning embraces perceptions and capacities of individuals such as; willingness to share ideas/information, participation by all stakeholders, continuous interaction and feedback, flexibility in planning and implementation (Mudombi et al., 2017). Institutional social learning involves features and policy that produce a conducive atmosphere and enhance social learning like; presence of processes to translate feedback into changed practices, support for locally initiated projects, and development of local stakeholders' capacity to engage with projects or interventions (Mudombi et al., 2017). When these individual and institutional factors are harnessed they enhance social learning for complementary strategies that facilitate forest resource management Figure 9.

Published by SCHOLINK INC. 


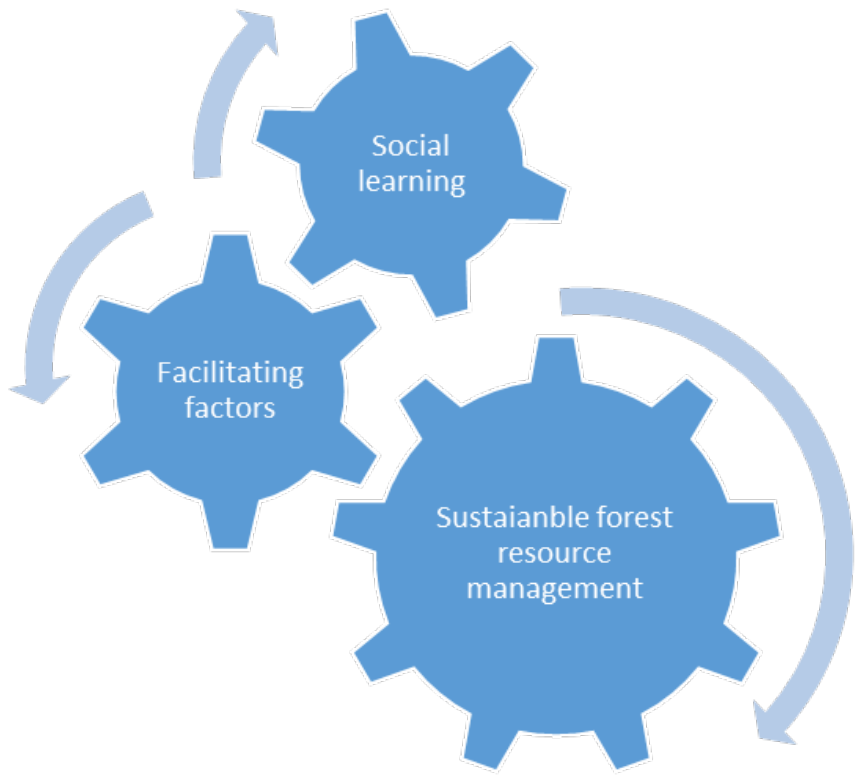

Figure 9. Social Learning as a Vehicle for Facilitating Communal Forest Resource Management

In addressing the main research question as to how social learning can be employed as a vehicle for facilitating complementary strategies in forest resource management, it is necessary to consider the individual and institutional contexts.

4.1 Addressing Individual Level Social Learning Factors to Boost Complementary Strategies in Forest Resources Management

Awareness creation must be increased to conscientise people on the risk of woodfuels. This is necessary as people are used to collecting fuel free of charge and thus making the shift will involve a lot of education as surmised by respondents A, B and C. The significance of sensitisation cannot be overemphasized, respondents who suggested interest for clean fuels like LPG had been previously exposed to it in a different place. For example a respondent in Murugu (Figure 3 one of the study sites) was using charcoal for cooking during her marriage to a partner in the southern part of Ghana, where charcoal use is more common. Although she is now relocated to a new area where use of fuelwood is more prevalent, she still adheres to charcoal use because she is used to it. Other respondents who opted for LPG had seen their relatives use it in urban towns and thus preferred it. Although there is willingness to shift to alternative fuels to help limit deforestation, change is a gradual (Mundumbi et al., 2017) process (Figure 1) hence to make change more sustainable it needs to be incremental (Sayer et al., 2013). This includes the idea by a local energy provider SIMAVI (represented by respondent A) to introduce propane bottles which can be employed like gas cylinders. The propane bottles are comparatively cheaper than the gas cylinders and less costly to fill. Given that people in rural areas gather fuelwood for free this would be more attractive to them in terms of cost compared to relatively bigger and more expensive gas cylinders. Similarly respondent E from the Energy commission indicates reducing cylinder sizes into bottles in the near future. Respondent $\mathrm{E}$ further surmises that the Published by SCHOLINK INC. 
commission is designing a distribution plan where for example a consumer takes an old bottle and sends to retailer in return for a new one. This is parallel to the practice of bottle picking whereby people pick old bottles for the breweries in return for money in many parts of the country. Furthermore, the government will provide the bottles free of charge whiles consumers only pay for the content according respondent $\mathrm{E}$.

Livelihood diversification; diversification due to the adoption of alternative livelihoods will also have a positive impact on forest resource conservation as it will reduce pressure on natural resources due to the abundance of options (Ellis, 2000). The heavy reliance on woodfuel is having a negative impact on rural agriculture which is the main income source of the rural community. The cutting and felling of tree cover has led to rampant erosion of topsoil and loss of soil fertility (Respondents B and F). The habitat of wild animals have also been negatively affected. A survey conducted within the fringe communities of the Mole National Park indicates that communities attest to the drastic loss in animal populations and vegetation cover (increased vulnerability) over the years. Consequently animals that used to be commonly sighted are seldom spotted in recent times, whilst areas that used to be carpeted with thick vegetation are now bare (AROCHA, 2007). Diversification will however limit the pressure on environmental resources (reduced vulnerability) due to collection and gathering by rural dwellers (coping strategy) and hence boost conservation efforts (Ellis, 2002) as argued by respondent C. This phenomenon of collection and gathering embraces "firewood collection, charcoal production, gathering wild fruits and vegetables, and hunting wild animals” which represent the least return activities as per the rural economy (Ellis, 2002). The adoption of alternative livelihoods with their attendant increased income (livelihood outcome) per labour (Table 3) will be an incentive for switching labour time (Figures 5, 6, 7 and 8) from these activities. This was one of the key arguments of respondents A, C, E and F which are reflected in Ellis (2002) and Resurrection et al. (2012). Furthermore, enhanced income may facilitate switching in consumption patterns such as 49 kerosene substituting firewood, or LPG gas replacing charcoal (Figures 5, 6 and 7).

Familiarizing with contextual local communal norms and customs; knowledge of the livelihood patterns of a constituency to which a project is tailored is another important factor as suggested by respondent C. Understanding the norms and values of a people enhances success and resilience of livelihood enhancement programmes. Furthermore it reduces hostility of local people to social interventions as it takes into account their peculiar culture and lifestyles (UNESCO, 2002). A local chief surmises that trees, such as shear tree (Vitellaria paradoxa) and dawadawa (Parkia biglobosa) are prohibited for woodfuel due to the economic value attached to them by the local authority. Infringement comes with a corresponding penalty to deter its use. Gender roles in energy use, local traditions and prohibitions related to fuel as highlighted in the results section (results 3.1, 3.2) for example, should be taken into account in the design of policies targeted to such rural areas (Zhou et al., 2013) which respondents C, D, E and F concur. Institutions factors also complement individual social learning factors that can complement auxiliary strategies for forest resources management.

Published by SCHOLINK INC. 
4.2 Addressing Institutional Factors that can Enhance Social Learning and Boost Complementary Strategies for Forest Management

Appropriate technology makes use of local human resources in developing and managing technology. A respondent from a local university (Respondent D), posits that education of the girl child will help them supply positive feedback which can feed into design of cooking technology as they use it most. In the broader context formal education will ensure that there is always available skilled human resources which can manage and constantly develop technology to meet the needs of rural households (Zhou et al., 2013). Furthermore, the adoption of curricular in renewable energy or clean energy by educational institutions will further boost knowledge and skill (Zhou et al., 2013) as depicted in results 3.2. Students can be encouraged to take internships in the rural areas and be rewarded with credits or other incentives developed with corporate institutions as surmised by respondents D, E and F. This practical experience will all go a long way to developing human and institutional capital for developing and managing cleaner fuel options (Zhou et al., 2013) and help reduce pressure on scarce forest resources (Figures 2 and 8) for sustainable development (Sayer et al., 2013).

Remoteness is related with increased poverty and less livelihood opportunities (Ellis, 2000), thus it is plausible to target remote locales when devising policies and projects for addressing the rural energy challenge (Zhou et al., 2013). The case study area is largely remote (Figure 1), settlements are mainly dispersed and inaccessible (Figure 3) especially during the rainy season. In addition, out of the overall $432.5 \mathrm{~km}$ road network, majority of the roads are in a bad state and immotorable in the rainy season. Hence not more than $0.03 \%$ of the district roads are motorable year round except in the Damongo Township. Apart from the Damongo town roads, there is no single tarred road in the district. Most of the roads in the district are feeder roads and are often flooded and impassable during the rainy season. Roads in the area constitute the physical capital component of sustainable livelihood framework which require improvement by government as a mediating institution to facilitate access and thus enhance the rural energy needs (Scoones, 1998). Tarring of the roads will open up the district to investors and tourists. Price and reliability were some of the main concerns of respondents (Figures 6 and 7). Improved roads will ensure that prices of modern fuels are affordable for the rural poor and afford timely delivery of energy services to guarantee the reliability of such services as argued by respondents A, D and E. This will contribute to efforts at reducing pressure on forests for woodfuels which is depleting ecosystem resources (Figures 2 and 8). Case study results indicate the relationship between location of respondent and type of fuel used was also significant. Respondents from the rural areas used mainly firewood whilst in Damongo (District Capital) there was a marked shift towards use of charcoal and LPG.

Respondent B postulates that in sub-Saharan African countries there is a relatively less proportion of local risk-taking entrepreneurs (human capital) to take over medium and large scale industry (physical capital). This scenario has led to a situation where business ownership is concentrated in the hands of a few domestic elites which have stifled competition (transforming process). The private sector will thus Published by SCHOLINK INC. 
have to be less risk averse and venture into the energy sector and consequent contribute to efforts (Figures 1 and 9) at limiting pressure on forest resources (Respondents A, E and F). When conditions are favourable such as good roads and policies (Scoones, 1998), the private sector will automatically move into energy production as argues by respondents A and E. The Energy Commission suggests private organizations involved in the energy sector have united (social capital) to form an organization to help shape policy and also enhance streamlining of standards (transforming process) in the energy sector. This will ensure high quality fuel is delivered to the rural communities and facilitate the adoption of clean production techniques (Zhou et al., 2013). Though the private sector is making progress in attempting to satisfy the household energy demand with, clean-efficient fuels (solar, briquettes, gas) there is still a gap between demand and supply (Energy Commission, 2012). This gap will be effectively bridged through effective collaboration between the key mediating institutions such as government and the private sector (Scoones, 1998).

4.2.1 Local Materials That Can Be Developed into Producing Fuel Alternatives to Reduce Pressure on Forest Resources

Land, a physical asset in the case study area can be used for forest plantations which will help reduce pressure on forest reserves (natural capital) (Scoones, 1998). Wood species which reproduce faster and produce much denser and efficient fuel (such as bamboo) can be planted to improve house energy in the rural communities (respondent E). With regards to appropriate technology, the Energy Commission is promoting sustainable woodlot cultivation with a pilot project. Moreover the production technology is being enhanced. The traditional carbonisation technology using the earth mound is inefficient thus it wastes a lot of wood to produce little charcoal (Appendix) as surmised by respondent F. Consequently, the Energy Commission is promoting the use of improved technology like the cylindrical metal kiln, brick kiln which produce much denser fuel and are more efficient in their wood to energy conversion. Waste to energy; not all parts of the felled tree are used for charcoal production; for every tree felled about 20-30 percent goes into "waste" (Energy Commission, 2012). The abundance of agricultural wastes such as corn husks, millet husks, animal dung points to usage of briquettes. These briquettes are much denser and the production is efficient. The briquettes (Appendix) produce little pollution and make use of abundant waste materials (Respondent E). This is in line with appropriate technology concept of using readily available local materials to limit production costs (Zhou et al., 2013).

Solar energy; solar energy has been ustilised for electricity generation, drying of crops and water heating (Appendix), however not on a large scale (Energy Commission, 2012). The Kumasi Polytechnic currently has produced a solar cooking stove and oven (Appendix). However the challenge with this device is that, it can only be used with good solar radiation suggested respondent D. Thus on cloudy days, or other parts of the day with low solar radiation this is not possible. This device can therefore be used as a complement to other stoves. The abundant solar energy is natural capital as per the sustainable livelihood framework which mediating institutions like the Government and Research Institutions (Scoones, 1998) can transform via appropriate technology into modern fuel options as is Published by SCHOLINK INC. 
being done by the Kumasi Polytechnic. On the whole there are varied possibilities for reversing the present heavy dependency on woodfuels (Figures 5 and 7), however the main challenge is with making these alternatives accessible to the rural households (Respondents A, D, E and F). This is one vital role of the mediating institutions like government, companies and organisations in the private sector (Scoones, 1998).

Thus ultimately when the individual and institutional factors in social learning are harnessed to complement strategies at reducing pressure on forest resources (Figure 9), it enhances rural livelihoods and comes with positive spin-offs for sustainable development (Figure 2).

\section{Conclusions}

Energy supplies services to satisfy several essential basic human needs (cooking, heating, light). Trade, commerce and public services viz; modern healthcare, education and communication are also highly reliant on access to energy services. Majority of Ghana's energy is obtained from biomass; hence more than $80 \%$ of households use biomass as their primary cooking fuel especially in impoverished rural communities. This comes with attendant pressures on communal forest resources resulting in ecosystem degradation. Complementary strategies for people to adopt alternative energy sources to reduce pressure on forest resources can greatly be facilitated by social learning.

Alternative energy options have been developed whilst others are at an advanced stage of development such as briquettes, bamboo charcoal, propane gas bottles, solar cookers, waste to energy amongst others, however they are not yet accessible to the rural populace. Moreover, these are beyond the financial means of rural households where wood fuels usage is predominant.

Results indicate that reversing the current levels of wood fuel use is possible to the barest minimum when social learning is harnessed. This will involve change in attitudes, massive education/awareness creation, alternative livelihoods as well as appropriate technology. Government and private sector must adopt proactive policies and interventions that incorporate local needs and norms to encourage buy-in using social learning.

\section{References}

AROCHA. (2007). Baseline Socio-Economic Report Of Kaden And Yazori Communities.

Bagoora, F. (2012). Potential and climate change vulnerability, impacts and adaptation options in African mountains. In International Conference of Mountain Countries Climate Change in Kathmandu, Nepal (p. 94 slides).

Dyer, J., Stringer, L. C., Dougill, A. J., Leventon, J., Nshimbi, M., Chama, F., ... Syampungani, S. (May, 2014). Assessing participatory practices in community-based natural resource management: Experiences in community engagement from southern. Africa Journal of Environmental Management, 137(1), 137-145. https://doi.org/10.1016/j.jenvman.2013.11.057

Elbra, A. D. (2013). The forgotten resource curse: South Africa's poor experience with mineral Published by SCHOLINK INC. 
extraction. Resources Policy, 38(4), 407-744. https://doi.org/10.1016/j.resourpol.2013.09.004

Ellis, F. (2000). Rural Livelihoods and Diversity in Developing Countries. In Business \& Economics. Oxford: OUP.

Energy Commission Ghana. (2012). Sustainable Energy for All (SE4all)-Ghana Action Plan. Retrieved July 6, 2013, from http://energycom.gov.gh/files/SE4ALL-GHANA\%20ACTION\%20PLAN

Fisher, M., Chaudhury, M., \& McCusker, B. (2010). Do Forests Help Rural Households Adapt to Climate Variability? Evidence from Southern Malawi. World Development, 38(9), 1241-1250. https://doi.org/10.1016/j.worlddev.2010.03.005

Global Alliance for Clean Cookstoves. (2012). Ghana Market Assessment Sector Mapping. Retrieved July 6, 2013, from http://cleancookstoves.org/binary-data/RESOURCE/file/000/000/162-1

IISD. (2013). UNFCCC Expert Meeting on Technology Roadmaps Bulletin. Retrived May 30, 2013, from http://www.iisd.ca/download/pdf/sd/crsvol205num4e

Kerr, J. M., Vardhan, M., \& Jindal, R. (2010). Incentives, conditionality and collective action in payment for environmental services. International Journal of the Commons, 8, 595-616. https://doi.org/10.18352/ijc.438

Kvale, S., \& Brinkmann, S. (2012). Interviews-Learning the Craft of Qualitative Research Interviews. European Accounting Review, 21(1).

Leach, M., Mearns, R., \& Scoones, I. (1999). Environmental Entitlements: Dynamics and Institutions in Community-Based Natural Resource Management Milestones and Turning Points in Development Thinking Part of the series. IDS Companions to Development, 218-233.

Mudombi, S., Fabricius, C., Van, Z.-B. V., \& Patt, A. (2017). The use of and obstacles to social learning in climate change adaptation initiatives in South Africa, Jàmbá. Journal of Disaster Risk Studies, 9(1). https://doi.org/10.4102/jamba.v9i1.292

Office for Human Research Protection. (2012). The Belmont Report. Retrieved November 12, 2012, from http://www.hhs.gov/ohrp/humansubjects/guidance/belmont.html

Resurreccion, B. P., \& Elmhirst, R. (2012) Gender and Natural Resources Mangement:Livelihoods, Mobility and Interventions (p. 288). Earthscan. Retrived June 16, 2017, from https://www.staff.ncl.ac.uk/david.harvey/AEF806/Sconnes1998

Rittel, H. W. J., \& Webber, M. M. (1973). Dilemmas in a general theory of planning. Policy Sciences, 4(2), 155-169. https://doi.org/10.1007/BF01405730

Sayer, J., Sunderland, T., Ghazoul, J., Pfund, J.-L., Sheil, D., Meijaard, E., ... Buck, L. E. (2013). Ten principles for a landscape approach to reconciling agriculture, conservation, and other competing land uses. Proceedings of the National Academy of Sciences, 110(21), 8345-8348. https://doi.org/10.1073/pnas.1210595110

Scoones, I. (1998). Sustainable Rural Livelihoods. A Framework For Analysis. Ids Working Paper 72.

UNESCO. (2002). Cultural Diversity and Biodiversity for Sustainable Development. Retrived June 16, 2017, from 
http://portal.unesco.org/en/ev.php-URL_ID=6125\&URL_DO=DO_TOPIC\&URL_SECTION=201 .html

Zhou, Z., Dionisio, K. L., Arku, R. E., Quaye, A., Hughes, A. F., ... Ezzati, M. (2011). Household and Community Poverty, Biomass Use, and Air Pollution in Accra, Ghana. Proceedings of the National Academy of Sciences, 108(27). 11028-11033. https://doi.org/10.1073/pnas.1019183108

\section{Appendix}

Appendix 1.

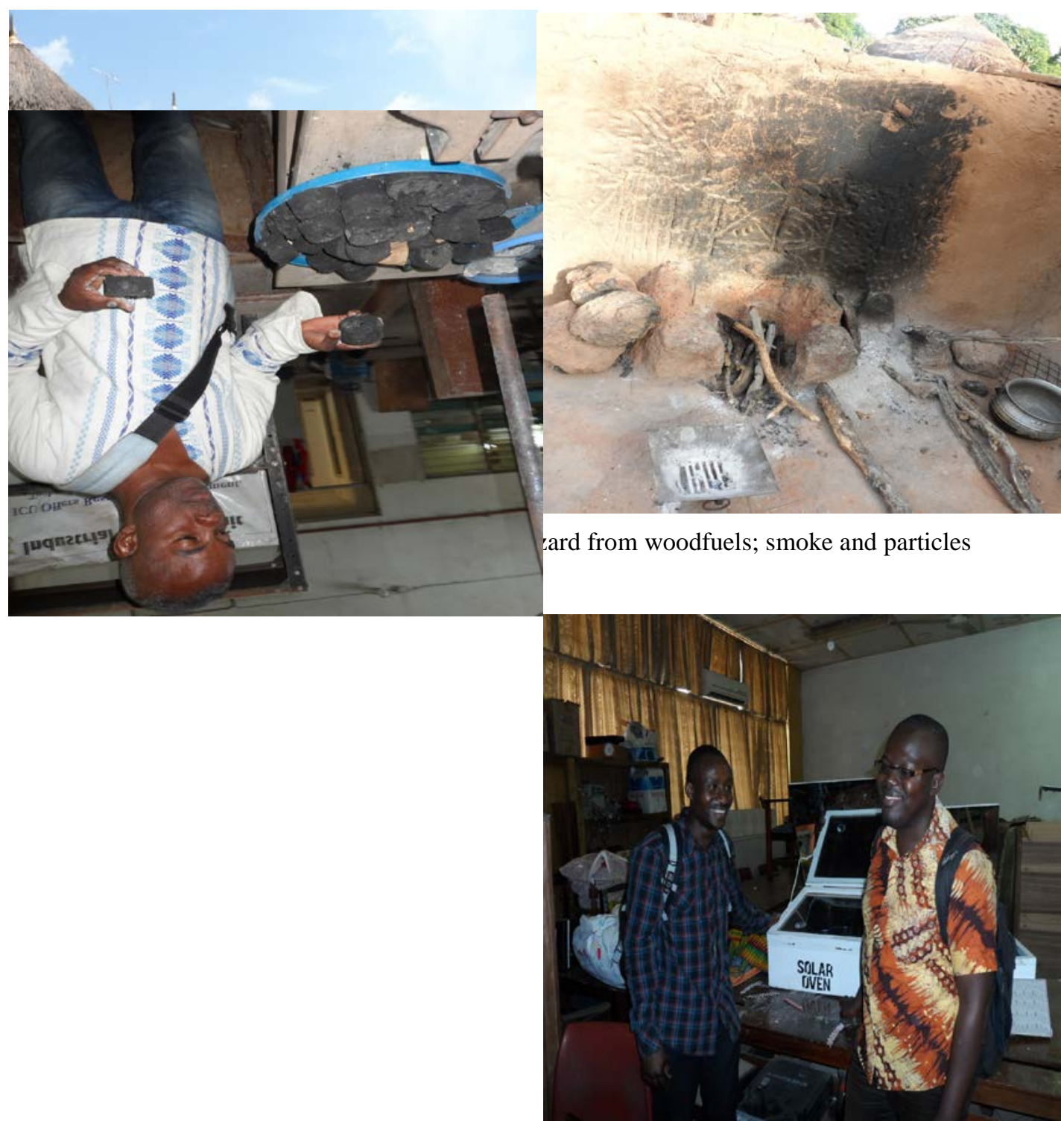

Use of briquettes Solar cooker 